Gut, 1972, 13, 31-32

\title{
Effect of intravenous metoclopramide on gastrooesophageal reflux
}

\author{
J. N. GLANVILLE AND W. D. WALLS \\ From the Departments of Diagnostic Radiology and Medicine, Chapel Allerton Hospital, Leeds
}

SUMMARY The effect of intravenous metoclopramide was studied radiologically in 40 patients with gastrooesophageal reflux. In no patient was reflux significantly diminished.

Metoclopramide activates gastrointestinal motility. It accelerates gastric emptying (Jacoby and Brodie, 1967; Connell and George, 1969; Kreel, 1970; Howels, Khanam, Kreel, Seymour, Oliver, and Davies, 1971) and stimulates contraction of the small bowel (Tinker and Cox, 1969). These effects may be due to activation of intramural cholinergic motor mechanisms (Jacoby and Brodie, 1967; Eisner, 1968). It is widely used as an antiemetic and is useful in controlling the symptoms of flatulent dyspepsia, including heartburn (Johnson, 1971).

In 1970 Heitmann and Möller (1970) reported that intravenous infusion of metoclopramide into normal subjects significantly increased gastrooesophageal sphincteric pressure and also the strength and duration of peristaltic waves in the lower oesophagus. Neither relaxation of the sphincter in response to swallowing nor the normal reflex rise in sphincter pressure resulting from an increase in intraabdominal pressure were impaired. Thus in patients with oesophageal reflux, metoclopramide may increase gastrooesophageal sphincter pressure to levels exceeding intraabdominal pressure and thereby prevent reflux. We have investigated this possibility radiologically.

\section{Patients}

Three groups were investigated.

GROUP 1

Twenty patients with radiologically demonstrable hiatus hernia and gastrooesophageal reflux.

GROUP 2

Twenty patients with radiologically demonstrable gastrooesophageal reflux but without hiatus hernia.

GROUP 3

Fifteen patients with symptoms suggestive of gastro-

Received for publication 2 November 1971. oesophageal reflux but without radiological abnormality.

\section{Method}

The usual radiological mucosal studies of the upper gastrointestinal tract were performed in the erect, supine, and prone positions. A further $200 \mathrm{ml}$ of barium suspension (Micropaque, Damancy \& Co.) was given. With the patient in the supine left posterior-oblique position, the clenched, gloved left hand was firmly pressed into the lower epigastrium. Hiatus herniation and gastrooesophageal reflux were then looked for during normal and deep breathing and swallowing movements. If no abnormality was seen, the left anterior oblique position was assumed with firm maintenance of abdominal pressure, and further screening with deep breathing and swallowing was performed.

If a hiatus hernia or gastrooesophageal reflux was not demonstrated, the patient was turned supine with a folded pillow beneath the abdomen and reexamined at rest and whilst swallowing barium sucked through a straw.

The patient was then turned into the left lateral position to maintain the barium in the fundus. Ten mg of metoclopramide was given intravenously. After intervals of five and $\mathbf{1 0}$ minutes, when gastric peristalsis had been seen to increase, the above procedure was fully repeated.

Screening was performed with image intensification and recorded on $70 \mathrm{~mm}$ film. Every effort was made to keep radiation to a minimum.

\section{Results}

No reduction in the degree of reflux was observed in any patient in groups 1 or 2 either five or ten minutes after the administration of metoclopramide. Occa- 
sionally, we gained an impression that reflux increased slightly following metoclopramide in groups 1 and 2. This led to the investigation of patients in group 3 but none developed reflux after receiving metoclopramide.

\section{Discussion}

These results are disappointing in view of the encouraging increase in pressure at the gastrooesophageal sphincter reported by Heitmann and Möller (1970). They, of course, were dealing with healthy subjects with presumably normal sphincters in contrast to our groups 1 and 2 . It was also noted, however, that even in normal subjects, the lower the initial sphincter pressure the less was the increase in response to metoclopramide. Thus as patients with reflux have lower sphincter pressures than subjects without reflux (Cohen and Harris, 1971) the lack of response of groups 1 and 2 might be expected.

An alternative, but unlikely, explanation for the apparent discrepancy between our results and those of Heitmann and Möller (1970) is that they gave metoclopramide by intravenous infusion at 0.4 $\mathrm{mg} / \mathrm{min}$ for $50 \mathrm{~min}$ recording pressure changes 10 min after starting the infusion, whereas we gave
$10 \mathrm{mg}$ as an intravenous bolus reassessing the degree of reflux at five and 10 minutes.

It is concluded that under the conditions of this investigation metoclopramide did not diminish oesophageal reflux and therefore is unlikely to benefit patients with reflux oesophagitis. However, the possibility that a more prolonged course of oral metoclopramide may be more effective than a single intravenous dose is about to be investigated.

\section{References}

Cohen, S., and Harris, L. D. (1971). Does hiatus hernia affect competence of the gastroesophageal sphincter? New Engl.J. Med., 284, 1053-1056.

Connell, A. M., and George, J. D. (1969). Effect of metoclopramide on gastric function in man. Gut, 10, 678-680.

Eisner, M. (1968). Gastrointestinal effects of metoclopramide in man. In vitro experiments with human smooth muscle preparations. Brit. med. J., 4, 679-680.

Heitmann, P., and Möller, N. (1970). The effect of metoclopramide on the gastroesophageal junctional zone and the distal esophagus in man. Scand. J. Gastroent., 5, 621-625.

Howells, T. H., Khanam, T., Kreel, L., Seymour, C., Oliver, B., and Davies, J. A. H. (1971). Pharmacological emptying of the stomach with metoclopramide., Brit. med. J., 2, 558-560.

Jacoby, H. I., and Brodie, D. A. (1967). Gastrointestinal actions of metoclopramide. Gastroenterology, 52, 676-684.

Johnson, A. G. (1971). Controlled trial of metoclopramide in the treatment of flatulent dyspepsia. Brit. med. J., 2, 25-26.

Kreel, L. (1970). The use of oral metoclopramide in the barium meal and follow-through examination. Brit. J. Radiol., 43, 31-35.

Tinker, J., and Cox, A. G. (1969). Effect of metoclopramide on transport in the small intestine of the dog. Gut, 10, 986-989. 